\title{
Building a better ecosystem for supporting our communities and the role of evaluation Kate Frykberg
}

Based on a keynote presentation to:

The convergence of evaluation and impact measurement

Annual Conference of the Aotearoa New Zealand Evaluation Association

Te Papa, Wellington, 19 July 2016

"Why does everyone seem unhappy about how the evaluation system works? And if we are all unhappy, why can't we do something about it?" This question came from a conversation with impact measurement and evaluation specialist David Pritchard, ${ }^{1}$ a fellow speaker at the ANZEA conference 2016. David's question got me thinking, and this article explores the dynamics within the ecosystem for supporting our communities, the role of evaluation, and how we might improve things.

I am not an evaluation expert, and the following is a funder's perspective based on my observations as a chief executive, trustee,

1 https://www.linkedin.com/in/david-pritchard-39aba3 
and consultant in the philanthropic sector in Aotearoa New Zealand. Funders want to put their money where it makes the most difference, so therefore evaluation should be a funder's best friend, right? And yet I find myself filled with nagging doubts. Are the evaluations I see telling me the full story? Can I interpret them usefully? And how much am I, as a funder, responsible for the general unhappiness in our ecosystem?

\section{Delving into the community sector ecosystem}

Let's start by looking a bit deeper into the community sector ecosystem and how evaluation fits in. It seems to me that the system has four key players:

- communities

- NGOs

- funders

- evaluators.

Let's look at the relationships and transactions that occur between these players. Let's tell a story ...

Figure 1 shows the key players in this imaginary story. But instead of the vague term "communities", let's talk about young people. And not just generic young people, this is about 15 year olds Sione and Krystal. Sione has hardworking parents who both work two minimum-wage jobs; he doesn't see them much. Krystal's in her fourth placement in State care. Sione and Krystal both have stuff going on in their lives and have both been in trouble with the police. 


\section{Delving deeper into the ecosystem}

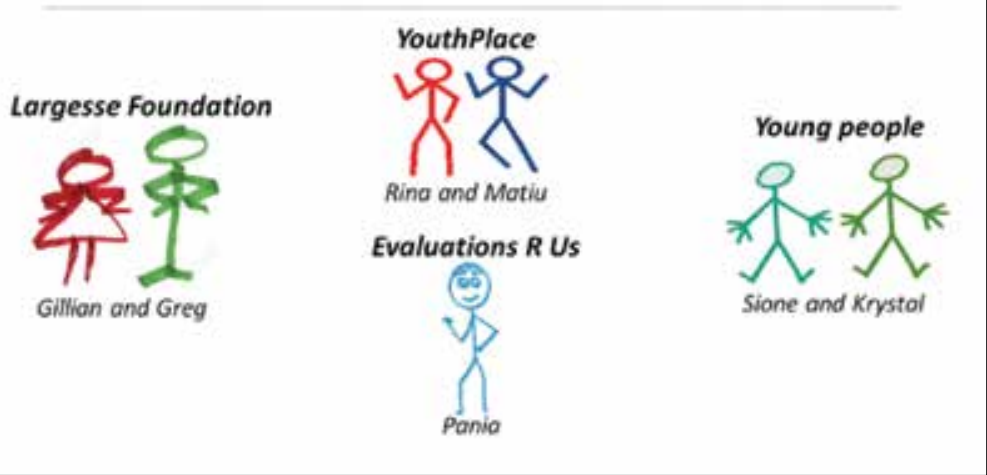

Figure 1. Key players

Then there is the local NGO called YouthPlace, managed by Rina, and employing a talented youth-worker, Matiu. YouthPlace has a good reputation: it provides health services, has a homework centre, there's kapa haka and counselling and street art and a gym-it's built around the young people. Sione and Krystal love Matiu; he's fun, he listens, and he cares. Matiu got Sione into the volleyball team, while Krystal, after some persuasion, has joined the kapa haka group and she's got a voice like an angel. Things are kind of working.

The third player in our story is a one of the key funders in the region-let's call it the Largesse Foundation. Local accountant Gillian is a dedicated trustee of the organisation and Greg is their hardworking CE.

Then there is Pania, an experienced and respected evaluator working in a small company called Evaluations R Us. But she is not in the story yet.

Rina at YouthPlace is having sleepless nights because funding is tight and she is worried about how to pay Matiu's salary. Largesse Foundation funds youth mentoring, so she says to Matiu, "We can 
do some mentoring can't we?" and Matiu says, "I don't know, our young people aren't really asking for it." She says, "Well we might as well, there's no harm in it." So Matiu agrees to provide group mentoring sessions, and Rina applies for funding to Largesse Foundation. YouthPlace receive funding for one year and for a time all seems well.

The year passes and Rina asks Greg if she can reapply for funding. "Yes of course," says Greg, "but we require an independent evaluation so we understand what impact the mentoring is making." Rina asks politely if the independent evaluation will be funded by the foundation. "Unfortunately not," responds Greg.

What has gone on in the background here? The foundation's trustees, led by Gillian, care deeply about doing the right thing and funding the most effective initiatives. Evaluation is seen as a scientific tool for achieving this, hence the requirement for independent evaluation. They also assume that evaluation can and should be done as business as usual in all NGOs and it doesn't occur to them that additional funding will be required.

So, now our evaluator Pania comes into the story. Rina at YouthPlace gives her a call and asks whether Pania can do some evaluation work. Pania says, "What's the evaluation question?" Rina replies, "The funder wants to know if our youth mentoring is working." Pania says, "So what information are you collecting now?" Rina isn't sure. Pania asks, "What's the budget for this work?" Rina says that she doesn't have any budget for this at all, but can hopefully find some kind of contribution.

Pania reluctantly agrees to undertake this work for a quarter of her normal rate. She talks to Sione and notes the positive changes happening. She starts to talk with Krystal - but the next day Krystal doesn't come in because her care placement had broken down and she has been sent to live with a family in Invercargill. Krystal is now counted as one of the programme's drop-outs. 
Despite the challenges, Pania writes a balanced, useful evaluation report. Rina gives this to the Largesse Foundation, Greg provides it to the Foundation trustees. At the board table, some trustees have read the report, some haven't. Of those who had read it, some take this very balanced view as evidence that the group mentoring at YouthPlace should be funded; some take it as evidence that it should not be funded.

They compromise and part-fund YouthPlace's group mentoring programme.

And the evaluation report is carefully filed for future reference, should it be required.

So-here we have an imaginary but plausible example of how the ecosystem for supporting communities and the role of evaluation plays out in practice. Even though everyone in this story is well intentioned and doing their best, David Pritchard is right-no-one is very happy.

- At Evaluations R Us, Pania is not happy because she did a lot of work for very little money and the evaluation report has not been used as she had hoped.

- At the foundation, Greg is not happy because he is embarrassed that a good organisation is receiving a cut in funding and he is the one who has to deliver the bad news. Gillian isn't happy either because she was hoping that an evaluation would give them a clear and simple answer on whether or not to fund-and it is now apparent that things are more complex than this.

- At YouthPlace, Rina is very unhappy because the part-funding means she can't cut the mentoring programme and she still needs to find funding for Matiu's salary. And she, Pania, and the young people all know that Matiu and his relationships have much more impact than the group mentoring. 
- Even Sione and Krystal are feeling a little uncomfortable. They enjoyed talking with Pania, she was pretty cool really. But now they have this sense of people out there who are observing them, examining them, that perhaps YouthPlace is not totally a place for them, but instead a place about them.

\section{What isn't working well in the evaluation system?}

I think that this story illustrates some key things which are not working well in our ecosystem for supporting communities and the role of evaluation within this.

1. Simplistic approaches and expectations. Communities and attempts at social change are messy and complex, and we sometimes believe that evaluation will provide quick and simple answers. In our story above, this was demonstrated by Gillian and her "out pops the answer" expectations. Sadly we often see this from funders, particularly those of us who have come from the world of business; the financial success of a business is significantly easier to measure than social impact.

2. Hidden agendas and unhelpful framing. Evaluations almost always have politics of some kind behind them, and it is useful to ask who is commissioning the evaluation and why. In our story Rina needed funding and an evaluation was needed to convince the funder. The reality was that peer mentoring (a bolt-on initiative to bring in funding) wasn't working particularly well; but overall YouthPlace was working fantastically. However the evaluation question was not how well the the organisation was working overall for the young people they served; instead it concentrated on one component only. Hidden agendas and the way an evaluation is framed can make it difficult to get to the heart of things.

3. Evaluation in isolation or as an afterthought. In our story, Pania was brought in long after the group mentoring had been set up. 
There was no co-design, no plan to collect the useful information and no evaluation budget. Furthermore, the evaluation was in isolation from the wider system — and that wider system includes practices such as transferring Krystal to Invercargill because her foster-care placement has broken down. The impact of this on Krystal's life will be far greater than the impact of the youth mentoring, and, through no fault of YouthPlace, the evaluation statistics will show that Krystal "did not complete" and may reflect badly on YouthPlace's work.

4. Attribution and contribution. Gillian very sensibly wanted to fund YouthPlace's group mentoring programme on the basis of whether it made a positive impact for their young people. The problem is that there are so many influencing factors. For Sione, is it the peer mentoring which made the difference? Being on the volleyball team? His loving aunty? Matiu's positive role-modelling? His own resilience and strength of character? Most likely it is some complex interplay between all these influences which supports positive change, and funding on the basis of one component only requires the presumption of attribution.

5. Measurability. At what point is Sione no longer likely to get in trouble with the police? We are not trying to measure widgets on a production line here, but rather social and personal change. People are not either compete or incomplete, functioning or not. Personal and societal change is an up-and-down process which may never truly end and is difficult to definitively measure.

6. Success theatre and vanity metrics. These are terms from the world of start-up businesses, which often experience similar problems proving their worth to potential investors. If YouthPlace's survival depends on funding, and funding depends on metrics, then it is almost impossible for Rina to resist "success theatre" that paints a rosy picture of the organisation, and she has powerful 
incentives to provide only the metrics that make YouthPlace look good-even if those metrics are not particularly meaningful.

7. Evaluations are surprisingly unhelpful for making funding decisions: One reason for this is the point above-when an evaluation reads more like a piece of marketing, most funders will be wary. Additionally, many evaluations compare "doing something" with "doing nothing" and these usually show that, yes, the initiative works much better than doing nothing. Well, you sort-of hope so surely? While it is useful to know that the initiative hasn't failed the first do-no-harm test of course, this doesn't really help for deciding which organisation to fund.

8. Perverse incentive to take the easy cases. This is one of the most insidious unintended consequences of linking funding to evaluation outcomes. If YouthPlace's funding depends on things such as completion rates of the mentoring programme, there is a disincentive to working with Krystal, because she has little stability in her home environment and the odds are stacked against her. Sione, with his comparatively stable family, is a much better bet. Who will work with those who most need support if funding rewards "cherry picking" those who are likely to succeed regardless? Are we asking organisations to choose between their own financial viability and taking on the people who need their support most?

9. Objectifies the people we work with. Somewhat related to the point above, funding dynamics may mean that YouthPlace's existence requires Sione and Krystal to be in difficulties, needs them to require "expert help" rather than turn to family and friends, and needs them to "recover" in the designated time period. There is a danger is that people become objectified, a "service user" and a checkbox on someone's reporting framework. In the story above, we saw how the very act of evaluation, even when done well, subtly changed the relationship between YouthPlace and Sione and Krystal. 
10. Equity and affordability. YouthPlace is a small, grass-roots organisation with little evaluation expertise and even less budget for commissioning expert assistance. Will only the large organisations thrive? The wise and often hilarious blogger $\mathrm{Vu}$ Le calls this the Data-Resource Paradox: "If an organisation does not have resources to collect data, then it does not have the data to collect resources.” (Le, n.d.).

\section{How we could work together to improve the community sector ecosystem}

So how can we rethink the practices and interrelationships within the community-sector ecosystem so that it might work a little better? Here are some suggestions.

\section{For evaluators}

1. Amplify the voice of communities. Who is it that an evaluator serves - the funder or NGO commissioning the evaluation, or the community? Does the work require a "political dance" to make the findings palatable? While the needs of whoever pays the invoice are undoubtedly important, even more important is to act in the interests of communities we all serve.

2. Train funders and NGOs in how best to commission and use evaluation. Understanding more about evaluation helps to challenge simplistic approaches and provides a space where people can share experiences, questions, and approaches.

3. Make meaning together. I find it helpful to sit down and work through the results of an evaluation in a workshop setting where we work collaboratively to explore questions of "what, so-what, and now-what". This approach is more likely to result in tangible and well-considered actions being taken than simply receiving a written report. 
4. Question and if necessary challenge funders. Because evaluators have some independence from the funder / funded relationship, and are called in because of expertise in the area, evaluators are better placed than most to educate and, where necessary, challenge simplistic approaches or bad practices among funders.

\section{For funders}

1. Provide long-term, enabling funding. In our story above, many of Largesse Foundation's funding practices were in need of improvement-for example:

a. Providing a single year of funding for an ongoing initiative then requiring YouthPlace to reapply from scratch wastes the time of both YouthPlace and the foundation staff and trustees. You can't change the world in a year.

b. Tying the funding to the mentoring initiative when the real need was for the youth-worker's salary inhibited the overall effectiveness of YouthPlace

c. Requiring but not funding an evaluation is unhelpful and unfair

In my experience, providing 2,3 , or even 5 years of funding to organisations which base what they do on a sound, plausible, and well-researched approach, are obviously constantly learning, represent the communities they serve and work from trust-based relationships with both their communities and their funders, usually results in clear impact. And providing funding for evaluation is important, particularly if the funder is requiring this.

1. Decouple evaluation from funding decisions. In some quarters decoupling evaluation from funding decisions would be considered heresy, however many analysts are now questioning this. ${ }^{2}$

2 Examples include articles by France's Pierre Calame (2016) and Britain's Caroline Fiennes and US analyst Ken Berger (2016). 
A better approach in my opinion is to fund an evaluation partway through a funding relationship when there is no incentive to hide the less-than-positive aspects. This approach avoids hidden agendas, supports the improvement process, and opens up honest conversations.

2. Look for evaluations that "improve rather than prove". The most useful evaluations in my opinion are those which show that the organisation is genuinely looking for what is working well, what isn't working so well, and what will improve things, and can then show what actions they are taking as a result. This indicates an organisation which is committed to constant learning and improvement and is prepared to be open and transparent.

3. Evaluate ourselves. If it's good for the goose, it's good for the gander-and trying to evaluate our own performance as a funder is a great lesson in the complexities of evaluation. A funder is only as effective as the organisation we fund, and understanding the sum impact of all funding decisions is a daunting task. Much easier, and still a useful exercise, is to evaluate the effectiveness of our strategies, processes, and relationships, and look for ways to improve what we do.

\section{For NGOs}

1. Ensure your organisation represents the communities you serve. Youth organisations need young people on their board and staff, same with those working with Māori, people with disabilities etc. "Nothing about us without us" is vital for creating positive impact.

2. Measure success in ways that are helpful to your community and you. Evaluations are tools for you and the people you serve, not funders. And happily many funders will welcome balanced and transparent evaluation reports. 
3. Question and if necessary challenge funders. Funders tend to live in a bit of a bubble. You can't easily go broke so there's no market forces to clean out the non-performers. And because of the inherent power dynamics, few people tell funders what they really think, sometimes resulting in a blissful unawareness of bad practice. Funders need constructive feedback.

\section{For communities}

1. Foster community-led initiatives. The defacto power structure in our sector is that a few funders decide which NGO's receive funding, who in turn decide which people receive their services. But really it should be the other way round, where we in the community look after ourselves and one another, and draw on specialist services from NGOs when required, who, in turn draw financial resources from funders. It would be great to have more community-led initiatives, and fewer top-down ones.

2. Be heard and be represented. Achieving the above requires providing feedback, voicing opinions, and sitting in rooms where decisions are made. We have more power than we think and can make our own change.

\section{For all of us}

1. Embrace complexity. We can all embrace complexity and accept that there are no easy answers. If poverty was an easy problem to solve, we would have solved it generations ago.

2. Take a systems perspective. Change happens both on a personal, family-by-family basis, and at a system level— at the kitchen table and the legislative chamber. We saw this in action with Krystal and Sione; the work of YouthPlace is "kitchen table"-local, oneon-one, interpersonal change. But there's also a whole system surrounding those young people. It is impossible for YouthPlace to counter the system-wide issues Krystal encounters and it 
would have been much better had she not experienced a series of foster care placements. Whether we are evaluators, non-profits, or funders, we need to ensure that our focus is not too narrow.

3. Act collectively. None of us can change the world alone. Collaboration and initiatives such as Collective Impact, which attempt to align all the players in our ecosystem as well as business, government, and others, have significant promise.

4. Put people and relationships at the centre of everything we do. Finally, relationships matter. If our relationships work, then we go a long way towards solving everything from child abuse to war.

In summary, I think that the answer to our original question about why is everyone unhappy about how the evaluation system works is that the relationships and dynamics between the various players in the ecosystem-communities, NGOs, funders, and evaluators - are not as good as they could be. Happily, there is much we can do to improve this.

As one of the speakers at the ANZEA 2016 conference said, "No matter what your mahi (work) is; relationships will make it or break it."

\section{References}

Calame, P. (2015, June). Philanthropy: Shifting from measuring impact to pursuing relevance [Web log post]. Retrieved from http://blog. pierre-calame.fr/post/2015/06/Philanthropy\%3A-shifting-frommeasuring-impact-to-pursuing-relevance- $\% 28$ Tribune-published-in-theApril-28th-2015-edition-of-the-French-newspaper-Le-Monde\%29

Fiennes, C. \& Berger, K. (2016, March 15). Oops: we made the non-profit impact revolution go wrong. Retrieved from http://www.alliancemagazine. org/analysis/oops-we-made-the-non-profit-impact-revolution-go-wrong/ 
Le, V. (n.d.) Weaponized data: How the obsession with data has been hurting marginalized communities [Web log post]. http://nonprofitwithballs. com/2015/05/weaponized-data-how-the-obsession-with-data-has-beenhurting-marginalized-communities/

\section{The author}

Kate Frykberg, Philanthropy and Community Consultant.

Email: kate@thinktank.co.nz 